\title{
Evaluation of an Intubation Readiness Score to Assess Neonatal Sedation before Intubation
}

\author{
Ellen H.M. de Kort ${ }^{a, b}$ Peter Andriessen ${ }^{a}$ Irwin K.H. Reiss ${ }^{b} \quad$ Monique van Dijk $^{b, c}$ \\ Sinno H.P. Simons ${ }^{b}$ \\ ${ }^{a}$ Department of Neonatology, Máxima Medical Center, Veldhoven, The Netherlands; ${ }^{b}$ Division of Neonatology, \\ Department of Pediatrics, Erasmus MC - Sophia Children's Hospital, Rotterdam, The Netherlands; ' ${ }^{\mathrm{D}}$ Department of \\ Pediatric Surgery, Erasmus MC - Sophia Children's Hospital, Rotterdam, The Netherlands
}

\section{Keywords}

Sedation · Newborn · Assessment · Intubation ·

Premedication

\begin{abstract}
Background: Premedication for neonatal intubation facilitates the procedure and reduces stress and physiological disturbances. However, no validated scoring system to assess the effect of premedication prior to intubation is available. Objective: To evaluate the usefulness of an Intubation Readiness Score (IRS) to assess the effect of premedication prior to intubation in newborn infants. Methods: Two-center prospective study in neonates who needed endotracheal intubation. Intubation was performed using a standardized procedure with propofol $1-2 \mathrm{mg} / \mathrm{kg}$ as premedication. The level of sedation was assessed with the IRS by evaluating the motor response to a firm stimulus ( $1=$ spontaneous movement; 2 = movement on slight touch; 3 = movement on firm stimulus; 4 = no movement). Intubation was proceeded if an adequate effect, defined as an IRS of 3 or 4, was reached. IRS was compared to the quality of intubation measured with the Viby-Mogensen intubation score. Results: A total of 115 patients, with a median gestational age of 27.7 weeks (inter-
\end{abstract}

\section{KARGER}

(c) 2018 S. Karger AG, Basel

E-Mail karger@karger.com

www.karger.com/neo quartile range 5.3) and a median birth weight of 1,005 g (interquartile range 940), were included. An adequate IRS was achieved in 105 patients, 89 (85\%) of whom also had a good Viby-Mogensen intubation score and 16 (15\%) had an inadequate Viby-Mogensen intubation score. The positive predictive value of the IRS was $85 \%$. Conclusions: Preintubation sedation assessment using the IRS can adequately predict optimal conditions during intubation in the majority of neonates. We suggest using the IRS in routine clinical care. Further research combining the IRS with other parameters could further improve the predictability of adequate sedation during intubation.

(c) 2018 S. Karger AG, Basel

\section{Introduction}

Endotracheal intubation is a frequently performed distressing procedure in the Neonatal Intensive Care Unit (NICU), and potentially complicated by a number of serious adverse physiological events [1-7]. Adequate sedation by the use of premedication before intubation may prevent these adverse events, reduces the duration and number of attempts needed for successful intubation, 
and prevents traumatic injury to the airway [3, 6-11]. Routine use of premedication before (semi-)elective intubation has increased over the past decades [12-18].

The main goal of premedication is to achieve an adequate level of sedation to facilitate the intubation procedure. Therefore, intubation should not be started until this level of sedation is achieved. However, there is no clear definition about the target level of sedation, and the assessment of sedation is often subjective and may vary between clinicians. The literature does not provide validated tools to assess the preintubation level of sedation [19].

In their study to evaluate the effect of methohexital as premedication in neonatal intubation, Naulaers et al. [20] described the effect of methohexital on sedation, relaxation, and sleep. The level of sedation was assessed as the motor response to a firm stimulus (heel-rubbing) and 4 degrees of reactions were defined: "moves spontaneously," "moves when touched," "moves when stimulated," and "no reaction to stimulus." Relaxation was assessed by evaluating muscle tone in arms and legs, using 4 categories: "hypotonic," "mildly hypotonic," "normal tone," and "hypertonic." The degree of sleep was noted as "awake," "easily woken," and "deep asleep." The results of this study show that the level of sedation, degree of muscle relaxation, and degree of sleep correlate very well [20]. Therefore, we judged the motor reaction to a firm stimulus to be a very useful and easy-to-perform score to assess the preintubation level of sedation and named this score the Intubation Readiness Score (IRS). The aim of our study was to evaluate the suitability of this IRS in adequately indicating the preintubation sedation level by correlating the IRS to the quality of intubation. We hypothesized that the IRS performed after the administration of premedication would adequately predict VibyMogensen intubation scores during intubation.

\section{Methods}

\section{Study Population}

This prospective two-center study was performed in the level III NICUs of the Erasmus MC - Sophia Children's Hospital, Rotterdam and the Máxima Medical Center, Veldhoven, both in the Netherlands, between June 2015 and January 2017. Patients admitted to one of these NICUs were eligible for participation in this study if they needed (semi-)elective endotracheal intubation. The exclusion criterion was participation in other premedication studies at the same time. We used the NEAR4KIDS registry definitions regarding intubation encounters and attempts. An encounter is defined as one attempt of completed advanced airway management intervention including tracheal intubation. An attempt is defined as a single advanced airway maneuver beginning with the
Table 1. Intubation readiness score

\begin{tabular}{ll}
\hline Score & Motor reaction to firm stimulus \\
\hline 1 & Spontaneous movement \\
2 & Movement in reaction to slight touch \\
3 & Movement in reaction to firm stimulus \\
4 & No movement
\end{tabular}

insertion of the laryngoscope into the patient's mouth and ending when the device is removed [21]. Because we allowed patients to be included in the analysis only once, we only included every first intubation attempt of every first intubation encounter per patient.

\section{Procedure}

Intubation was performed according to a standardized procedure. Propofol 1.0-2.0 mg/kg body weight was administered intravenously followed by a saline flush in $30 \mathrm{~s}$. Immediately after propofol administration, IRS was assessed every $30 \mathrm{~s}$ by firmly rubbing the heel of the patients' feet and grading the motor reaction to this stimulus (Table 1). Applying this stimulus and judging the reaction was always done by one of the team members performing the intubation procedure. Both scores 3 and 4 were presumed to indicate adequate sedation for the intubation procedure. Therefore, when a score of 3 or 4 was reached, intubation was proceeded. If the IRS was still 1 or 2 after $3 \mathrm{~min}$, an additional dose of propofol was administered, and again IRS was assessed every $30 \mathrm{~s}$. This procedure was repeated until IRS 3 or 4 was reached. The time frame of 3 min before administering a new dose of medication was based on the known fast onset of action of propofol. Intubation was performed by pediatric residents, neonatal nurse specialists, fellows in neonatology, and neonatologists.

\section{Outcome Measures}

The primary outcome of this study was the positive predictive value of IRS 3 and 4 in predicting good quality of intubation. The quality of the intubation was assessed with the standardized intubation score of Viby-Mogensen et al. [22]. Scoring included rating of laryngoscopy, vocal cords, coughing, jaw relaxation, and limb movements. Each item was assigned a score of 1-4 (Table 2). Good quality of intubation was defined as a score $\leq 2$ on each item. A score on one or more items of $\geq 3$ implied inacceptable quality of intubation.

\section{Data Collection}

Background characteristics as well as all IRS scores, data about all propofol doses, intubation conditions, and intubation attempts were collected on standardized intubation registration forms.

\section{Statistical Analysis}

SPSS (IBM SPSS Statistics for Windows, version 22.0. Armonk, NY, USA) was used to analyze the data. Relevant patient data were reported as numbers with percentages for nominal variables and median and interquartile ranges for continuous variables. Positive predictive values of IRS scores 3 and 4 combined as well as scores 3 and 4 separately, in predicting good quality of intubation, were determined (criterion validity). Univariate analysis was performed 
Table 2. Viby-Mogensen intubation score ${ }^{\mathrm{a}}$

\begin{tabular}{llllll}
\hline Score & Laryngoscopy & Vocal cords & Coughing & Jaw relaxation & Limb movements \\
\hline 1 & Easy & Open & None & Complete & None \\
2 & Fair & Moving & Slight & Slight & Slight \\
3 & Difficult & Closing & Moderate & Stiff & Moderate \\
4 & Impossible & Closed & Severe & Rigid & Severe \\
\hline
\end{tabular}

a Adequate intubation conditions were defined as a score $\leq 2$ on each item.

Fig. 1. Flowchart of study patients.

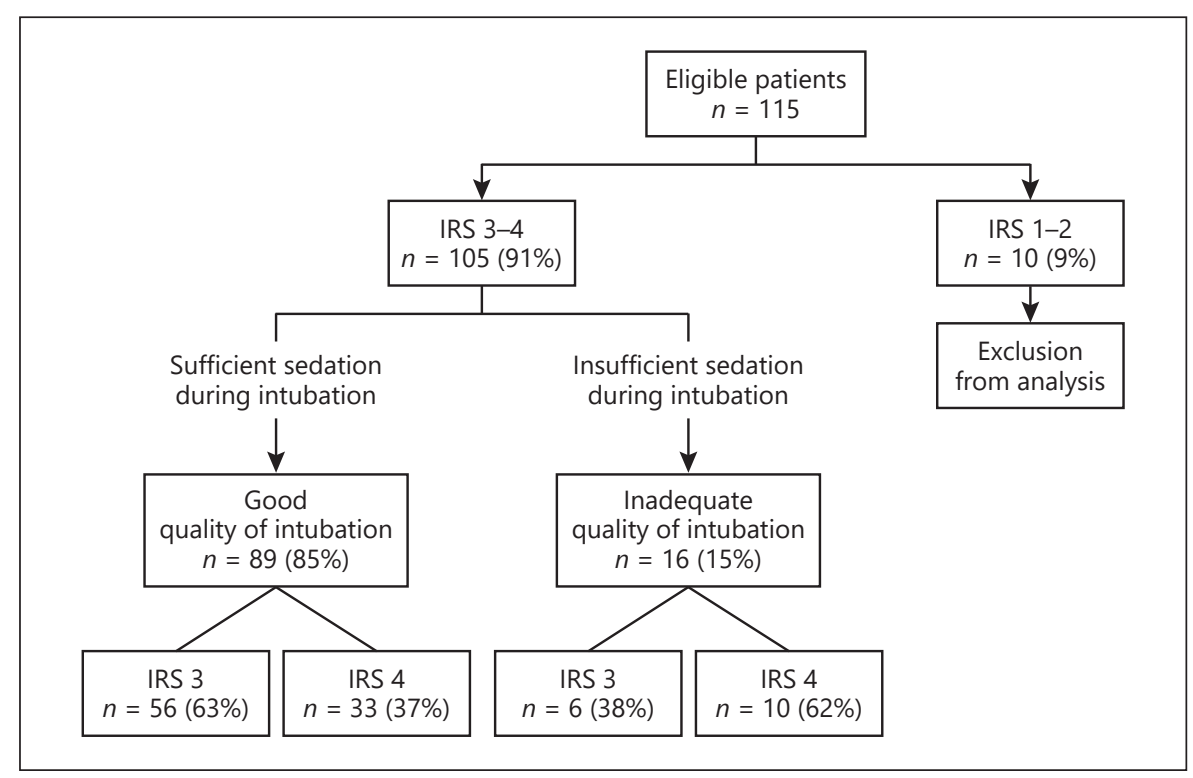

with Fisher's exact tests for categorical variables and the MannWhitney test for continuous variables. Two-tailed $p<0.05$ was considered statistically significant.

\section{Ethical Approval}

The IRS and Viby-Mogensen intubation score were implemented into daily practice as standard of care in both units because they potentially improved patient care. The study was judged as a prospective observational cohort study that did not incorporate extra risks or burden for the patients. Formal ethical approval to conduct the observational trial, according to the Dutch Law of Research with Humans, was not required (Medical Ethics Committee, Erasmus Medical Center, Rotterdam, the Netherlands, No. MEC-2017-240).

\section{Results}

\section{Study Population}

During the study period, 195 intubation encounters were performed in 164 patients. Only every first intuba- tion attempt of every first intubation encounter was included, and therefore 164 intubation attempts were eligible for inclusion. Of these, 49 attempts (30\%) were excluded because data regarding IRS and/or intubation scores were lacking or incomplete, leaving 115 intubation attempts eligible for analysis.

\section{IRS and Intubation Conditions}

IRS and intubation scores of the 115 patients that were eligible for analysis are shown in the flowchart in Figure 1. In 10 patients $(9 \%)$, intubation was started despite an IRS of 1 or 2, thereby violating the standardized protocol. These patients were excluded from further analysis. IRS 3 or 4 was achieved in 105 patients (91\%). Eighty-nine patients with IRS 3 or 4 had good quality of intubation, leading to a positive predictive value of $85 \%$. IRS was 3 in 62 patients, of whom 56 patients had good quality of intubation, leading to a positive predictive value of $90 \%$. IRS 4 was reached in 43 patients. Of these, 33 patients had 
Table 3. Comparison of patient characteristics in patients with good and with inacceptable Viby-Mogensen intubation score after adequate IRS

\begin{tabular}{|c|c|c|c|}
\hline & $\begin{array}{l}\text { Good Viby-Mogensen } \\
\text { intubation score }(n=89)\end{array}$ & $\begin{array}{l}\text { Inacceptable Viby-Mogensen } \\
\text { intubation score }(n=16)\end{array}$ & $\begin{array}{l}p \\
\text { value }\end{array}$ \\
\hline Male gender, $n(\%)$ & $51(57)$ & $10(63)$ & 0.79 \\
\hline Median gestational age, weeks & $27.7(6.8)$ & $27.5(5.2)$ & 0.51 \\
\hline Median birth weight, $g$ & $995(810)$ & $1,110(1,238)$ & 0.71 \\
\hline Median postnatal age, days & $1(4)$ & $0.5(1)$ & 0.07 \\
\hline Median amount of propofol doses & $2(1)$ & $1.5(1)$ & 0.87 \\
\hline IRS $3, n(\%)$ & $56(63)$ & $6(37.5)$ & 0.10 \\
\hline $\begin{array}{l}\text { Median time between reaching good IRS and starting } \\
\text { intubation, min }\end{array}$ & $1(2)$ & $1(2)$ & 0.57 \\
\hline
\end{tabular}

Figures in parentheses indicate interquartile ranges unless indicated otherwise.

good quality of intubation, leading to a positive predictive value of $77 \%$.

We performed a univariate analysis to search for factors that could explain why the IRS did not adequately predict the sedation level during intubation in $15 \%$ of our study population. The results of these analyses are shown in Table 3. This table shows that gender, gestational age, birth weight, postnatal age, weight at intubation, cumulative dose of propofol, amount of propofol doses, IRS being 3 or 4 , and time in minutes between reaching good IRS and starting the intubation did not differ significantly between patients who had good Viby-Mogensen intubation scores and patients who had inacceptable VibyMogensen intubation scores. In 55 of the patients with good Viby-Mogensen intubation scores and in 6 patients with inacceptable Viby-Mogensen intubation scores, the function of the person who performed the intubation was registered. In patients with good Viby-Mogensen intubation scores, the intubation was performed by a pediatric resident in 13 patients (24\%), a nurse specialist in 20 $(36 \%)$, a neonatal fellow in 5 (9\%), and a neonatologist in 17 patients (31\%). In patients with inacceptable VibyMorgensen intubation scores, intubation was performed by a pediatric resident in 3 patients (50\%), a nurse specialist in $1(17 \%)$, and a neonatologist in 2 patients $(33 \%)$. These differences were not statistically significant $(p=$ 0.28 ). The reason for intubation was reported for $87 \mathrm{pa}-$ tients with good Viby-Mogensen intubation scores and for 15 patients with inacceptable Viby-Mogensen intubation scores. Respiratory distress syndrome was the reason in $39(45 \%)$ and $11(73 \%)$ patients, respectively, and respiratory insufficiency was the reason in $45(52 \%)$ and 4
(27\%) patients, respectively. Three patients with good Viby-Mogensen intubation scores were intubated for elective reasons versus none of the patients with inacceptable Viby-Mogensen intubation scores. Differences in reasons for intubation between both groups were not statistically significant $(p=0.116)$.

\section{Discussion}

Premedication should be used for intubation in neonates whenever possible to minimize adverse physiological events, to reduce duration and number of attempts, to prevent traumatic injury to the airway, and to provide comfort. Accordingly, the intubation procedure should only be started when the given premedication has achieved a sufficient degree of sedation. However, validated objective scoring systems to assess the readiness for intubation are lacking [19]. This study aimed to evaluate the suitability of an IRS to assess if a newborn is ready for intubation after administration of premedication. We show that this IRS can predict good quality of intubation in $85 \%$ of patients.

In the literature, no previous studies can be found that investigated the readiness for intubation. A recent systematic review shows only 3 potentially suitable scoring systems, all of them not validated [19]. One of these scores is the sedation score described by Naulaers et al. [20] that we used to develop our IRS. Another score to assess the level of sedation prior to intubation in neonates is the "good sedation state" from Thall et al. [23]. This score is based on the Neonatal Pain, Agitation and Sedation Scale 
developed by Hummel et al. [24] and consists of 5 variables: crying/irritability, behavior state, facial expression, extremity tone, and vital parameters. Each item is scored on a 5-point scale from -2 , corresponding to highest sedation, to +2 , corresponding to highest infant discomfort. According to Thall et al. [23], good sedation for endotracheal intubation is defined as a total score between -7 and -3 . To the best of our knowledge, further evaluation of this score has not been performed. Though this score might reflect the degree of sedation very accurately, it is an extensive and time-consuming score that makes it less suitable to perform in a semi-acute situation. We have therefore chosen to further evaluate the sedation score of Naulaers et al. [20].

Adequate prediction of the quality of intubation in $85 \%$ of patients also means that in $15 \%$ of patients the IRS did not adequately predict the level of sedation during the intubation procedure. This might be explained by the fact that heel rubbing is a weaker stimulus than the introduction of the endotracheal tube into the nose or laryngoscopy. In this case, a stronger stimulus that better reflects the pain and stress of laryngoscopy and/or introducing the endotracheal tube into the nose should be used. However, introducing a stronger, repetitive stimulus, to evaluate the level of sedation, thereby repeatedly exposing neonates to painful stimuli, is considered unethical. Another explanation for inadequate prediction of the level of sedation by IRS could be the short period of action of propofol. This pharmacological characteristic can cause the medication effect to be already expired at the moment the intubation is started, despite an IRS of 3 or 4 just before. This would mainly be the case in patients in whom a long period of time elapsed between reaching IRS 3 or 4 and starting the intubation attempt. However, statistical analysis revealed no significant difference in this time between patients with good and with inacceptable intubation conditions. We included only patients who received propofol as premedication. Future studies that use other sedative drugs are needed to further evaluate the IRS, which would increase the generalizability of our findings.

In our study, IRS 3 and IRS 4 were both hypothesized to predict sufficient sedation for the intubation procedure. Therefore, we combined both scores in our evaluation. Taking both scores apart, we expected that IRS 4 would better predict sufficient sedation during intubation than IRS 3. However, the results of our study show a nonsignificant higher positive predictive value of IRS 3 compared to IRS 4 (90\% compared to $71 \%$, respectively, $p=0.10$ ). This could possibly be explained by the difference in patient numbers in both groups (56 vs. 33 ) or by

Evaluation of an Intubation Readiness

Score the hypothesis that in patients with IRS 4 propofol has already reached its peak effect and by the time intubation is started, the effect is expired.

Though we belief that a positive predictive value of $85 \%$ makes the IRS certainly suitable for clinical practice, we should seek for methods to further improve this positive predictive value. It might be valuable to combine the motor reaction to heel rubbing with the degree of muscle relaxation. In the original report of Naulaers et al. [20], the level of muscle relaxation was also scored on a 4-point scale $(1=$ hypertonia, $2=$ normal muscle tone, $3=$ mild hypotonia, 4 = profound hypotonia). Adding this relaxation score to our IRS could possibly increase the number of patients in whom effective sedation can adequately be predicted before the intubation is started. Using both the sedation and the relaxation score was already done by Smits et al. [25] studying propofol dosing in neonates. They defined sufficient relaxation as mild or profound hypotonia. However, no conclusions about the usability of both scores can be drawn from their results.

In this study, we did not determine interrater variability of the IRS. This is an important limitation of this study. Where "spontaneous movements" and "no movement at all" are obvious scores and will most certainly not lead to much disagreement between clinicians, more disagreement could arise with the items "movement in reaction to touch" and "movement in reaction to a firm stimulus." Besides this, there could be variation in the meaning of the term "firm stimulus." Thus, interrater variability in IRS should be determined.

In conclusion, our study shows that by using the IRS, $85 \%$ of patients are adequately sedated for the procedure. Our protocol also enables the standardization of a highly complex procedure in vulnerable patients. We therefore advocate that the IRS should be used in every neonate who receives premedication prior to intubation. Further research combining the IRS with other parameters such as degree of muscle relaxation could increase the predictability of adequate intubation conditions even further.

\section{Disclosure Statement}

All authors have no potential conflict of interest to disclose.

\section{Funding Source}

Fonds Nuts Ohra grant was received and S.H.P. Simons was funded by a personal grant from the Netherlands Organization for Scientific Research (40-00703-97-12494). 


\section{References}

1 Maheshwari R, Tracy M, Badawi N, Hinder $M$. Neonatal endotracheal intubation: how to make it more baby friendly. J Paediatr Child Health. 2016 May;52(5):480-6.

2 Marshall TA, Deeder R, Pai S, Berkowitz GP, Austin TL. Physiologic changes associated with endotracheal intubation in preterm infants. Crit Care Med. 1984 Jun;12(6):501-3.

3 Kelly MA, Finer NN. Nasotracheal intubation in the neonate: physiologic responses and effects of atropine and pancuronium. J Pediatr. 1984 Aug;105(2):303-9.

4 Millar C, Bissonnette B. Awake intubation increases intracranial pressure without affecting cerebral blood flow velocity in infants. Can J Anaesth. 1994 Apr;41(4):281-7.

5 Lemyre B, Doucette J, Kalyn A, Gray S, Marrin ML. Morphine for elective endotracheal intubation in neonates: a randomized trial [ISRCTN43546373]. BMC Pediatr. 2004 Oct; 4(1):20.

6 Bhutada A, Sahni R, Rastogi S, Wung JT. Randomised controlled trial of thiopental for intubation in neonates. Arch Dis Child Fetal Neonatal Ed. 2000 Jan;82(1):F34-7.

7 Oei J, Hari R, Butha T, Lui K. Facilitation of neonatal nasotracheal intubation with premedication: a randomized controlled trial. J Paediatr Child Health. 2002 Apr;38(2):14650.

8 Barrington KJ, Finer NN, Etches PC. Succinylcholine and atropine for premedication of the newborn infant before nasotracheal intubation: a randomized, controlled trial. Crit Care Med. 1989 Dec;17(12):1293-6.

9 Carbajal R, Eble B, Anand KJ. Premedication for tracheal intubation in neonates: confusion or controversy? Semin Perinatol. 2007 Oct; 31(5):309-17.
10 Kumar P, Denson SE, Mancuso TJ; Committee on Fetus and Newborn, Section on Anesthesiology and Pain Medicine. Premedication for nonemergency endotracheal intubation in the neonate. Pediatrics. 2010 Mar;125(3): 608-15.

11 Byrne E, MacKinnon R. Should premedication be used for semi-urgent or elective intubation in neonates? Arch Dis Child. 2006 Jan; 91(1):79-83.

12 Whyte S, Birrell G, Wyllie J, Woolf A. Premedication before intubation in UK neonatal units. Arch Dis Child Fetal Neonatal Ed. 2000 Jan;82(1):F38-41.

13 Chaudhary R, Chonat S, Gowda H, Clarke P, Curley A. Use of premedication for intubation in tertiary neonatal units in the United Kingdom. Paediatr Anaesth. 2009 Jul;19(7): 653-8.

14 Kelleher J, Mallya P, Wyllie J. Premedication before intubation in UK neonatal units: a decade of change? Arch Dis Child Fetal Neonatal Ed. 2009 Sep;94(5):F332-5.

15 Wheeler B, Broadbent R, Reith D. Premedication for neonatal intubation in Australia and New Zealand: a survey of current practice. J Paediatr Child Health. 2012 Nov;48(11):9971000.

16 Durrmeyer X, Daoud P, Decobert F, Boileau P, Renolleau S, Zana-Taieb E, et al. Premedication for neonatal endotracheal intubation: results from the epidemiology of procedural pain in neonates study. Pediatr Crit Care Med. 2013 May; 14(4):e169-75.

17 Simon L, Trifa M, Mokhtari M, Hamza J, Treluyer JM. Premedication for tracheal intubation: a prospective survey in 75 neonatal and pediatric intensive care units. Crit Care Med. 2004 Feb;32(2):565-8.
18 Sarkar S, Schumacher RE, Baumgart S, Donn SM. Are newborns receiving premedication before elective intubation? J Perinatol. 2006 May;26(5):286-9.

19 de Kort EH, Halbmeijer NM, Reiss IK, Simons SH. Assessment of sedation level prior to neonatal intubation: A systematic review. Paediatr Anaesth. 2018 Jan;28(1):28-36.

20 Naulaers G, Deloof E, Vanhole C, Kola E, Devlieger $\mathrm{H}$. Use of methohexital for elective intubation in neonates. Arch Dis Child Fetal Neonatal Ed. 1997 Jul;77(1):F61-4.

21 Nishisaki A, Turner DA, Brown CA 3rd, Walls RM, Nadkarni VM; National Emergency Airway Registry for Children (NEAR4KIDS); Pediatric Acute Lung Injury and Sepsis Investigators (PALISI) Network. A National Emergency Airway Registry for children: landscape of tracheal intubation in 15 PICUs. Crit Care Med. 2013 Mar;41(3): 874-85.

22 Viby-Mogensen J, Engbaek J, Eriksson LI, Gramstad L, Jensen E, Jensen FS, et al. Good clinical research practice (GCRP) in pharmacodynamic studies of neuromuscular blocking agents. Acta Anaesthesiol Scand. 1996 Jan; 40(1):59-74.

23 Thall PF, Nguyen HQ, Zohar S, Maton P. Optimizing sedative dose in preterm infants undergoing treatment for respiratory distress syndrome. J Am Stat Assoc. 2014 Sep; 109(507):931-43.

24 Hummel P, Puchalski M, Creech SD, Weiss MG. Clinical reliability and validity of the NPASS: neonatal pain, agitation and sedation scale with prolonged pain. J Perinatol. 2008 Jan;28(1):55-60.

25 Smits A, Thewissen L, Caicedo A, Naulaers G, Allegaert K. Propofol dose-finding to reach optimal effect for (semi-)elective intubation in neonates. J Pediatr. 2016 Dec;179:54-60.e9. 